\title{
Possibility of Using Eddy Current Evaluation of the Heat Treatment of Steel
}

\author{
Petr Beneš, Vojtěch Průcha, Jiř́i Hájek, Vilém Vítovec \\ Faculty of Mechanical Engineering, University of West Bohemia in Pilsen. Univerzitní 22, 30614 Plzeň. Czech Republic. \\ E-mail: pbenes@kmm.zcu.cz, vprucha@kmm.zcu.cz, hajek@kmm.zcu.cz
}

\begin{abstract}
There are a large number of special methods for exploring the internal condition of materials on the basis of eddy currents. A major use of this method can be seen in surface engineering, particularly in studying some state quantities of surface integrity. It is also an irreplaceable tool in surface engineering. The reason is that no other affordable method provides information on both the surface and the sub-surface regions, as the latter are difficult to reach by most other inspection methods. It must be noted that the sub-surface region is significant, and dictates, to a large extent, the behaviour of the overlying surface. This article explores another non-traditional application of eddy current inspection. The study presented here involves a use of this non-destructive testing method for carburizing verification and for detecting of amounts of retained austenite.
\end{abstract}

Keywords: eddy current, retained austenite, carburizing

\section{Introduction}

Non-destructive testing (NDT) of materials has been thriving recently, mainly due to a drop in the prices of NDT equipment. Major technical advancements and a surge in user demand in the field of ultrasonic and especially eddy current inspection methods were seen with the emergence of phased array testing.

There are a large number of routine technical problems, to which eddy current methods can be applied to advantage. These include detection of discontinuities and cracks, problems related to the thickness of films and coatings, checks for incorrect material types, corrosion detection, and others. This article, however, focuses on an application, in which eddy current methods have not been used yet. It is the carburizing verification and quantity determination of retained austenite in steel after completed quenching process. Here, the eddy current method eliminates, to some extent, the labour-intensive and very timeconsuming identification of work hardening in material by conventional destructive methods, such as metallographic examination, measurement of hardness and microhardness, and others. These parameters in surface and sub-surface regions can be measured using eddy current testing thanks to the generally-known physical finding that presence of retained austenite or carburized layer in a metallic or martensitic matrix has a profound effect on its electromagnetic properties and on the formation of eddy currents in such materiál $[1,2,3,4]$.

The vast versatility of the ET method will certainly soon lead to its greater adoption in mechanical engineering, especially in those applications with strict requirements for quality and safety of machinery. This will very likely be accelerated by new eddy current-based techniques, such as eddy current array (ECA) [5,6]

\section{Experimental - verification of chemical-ther- mal processing of gear wheels}

The gear wheels are typical of mechanical products whose final properties are achieved solely by means of chemical and thermal processing. In this experiment, carried out assessing the correctness of the chemical heat treatment - carburizing by using eddy currents. $18 \mathrm{Cr}-$ NiMo7-6 steel was used as the experimental material, which is widely used for the production of gears or other high-stressed mechanical components. The aim of the experiment was not only to assess the correctness of the carburizing, but also to determine the depth of carburizing using the eddy current method. The test specimens were made from a real semifinished product for the manufacture of a gearwheel. The samples were circular cross section of $35 \mathrm{~mm}$ in diameter. To unify the physical and chemical properties of the test samples normalising annealing was carried out. This annealing resulted in grain refinement and uniformity of grain. The chemical heat treatment process consisted of powder carburizing and subsequent quenching and tempering. Powder carburizing was carried out at $910^{\circ} \mathrm{C}$. In order to create different depths of carburizing, the carburizing was carried out for different times for the different samples, ie for 2, 4, 6, 9 and 12 hours. To achieve different depths of carburizing, two types of carburizing powder - KG30 - were used for carburizing to a depth of $0.6 \mathrm{~mm}$ and KG6 for carburizing to a depth of over $0.6 \mathrm{~mm}$. The quenching of samples after the carburizing process took place at $830^{\circ} \mathrm{C}$, while the soaking time at the austenitizing temperature was $40 \mathrm{mi}-$ nutes. Subsequently, some of the samples were cooled in oil and the remaining part in the water. Subsequently, all samples were subjected to tempering at $170^{\circ} \mathrm{C}$ for 120 min. In case of the oil-quenching specimens, the removal of the oxiding and decarburized layers was performed by means of grinding $(0.1 \mathrm{~mm})$ of this upper region of the samples. The main purpose of this operation was to determine whether and how the accuracy of the measurement affects the presence of the oxiding and decarburized layers which are always present on materials surface after the heat-treated in a certain amount.

For such treated samples, a conventional measurement of the depth of carburizing was carried out by measuring the $\mathrm{HV}_{1}$ hardness method. In this experiment as the depth of carburizing was considered depth where the hardness of the material corresponded to the hardness of the heat-untreated sample. 


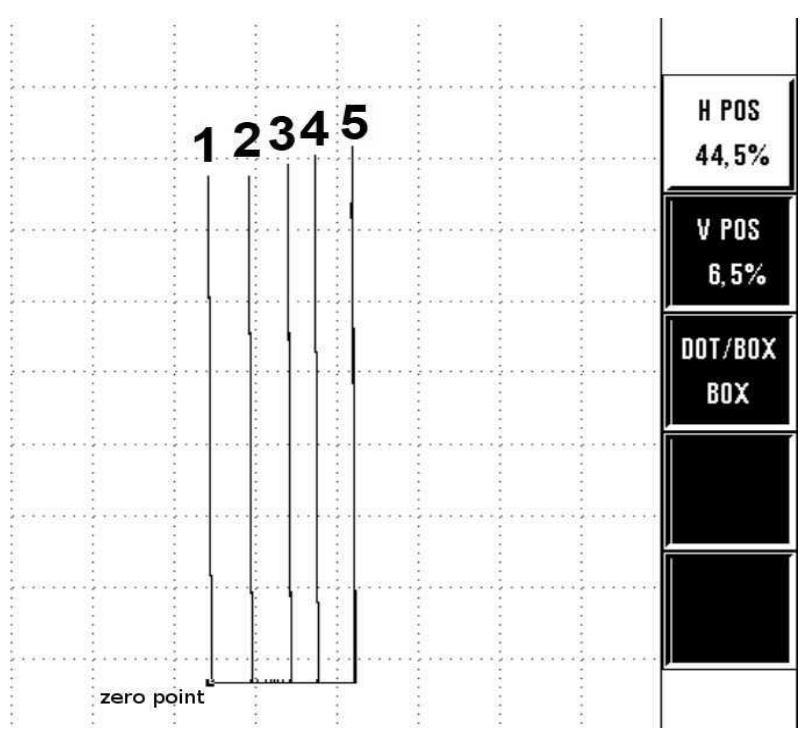

Fig. 1 Influence of carburizing depth on the trajectory of the working point in the impedance plane for variously samples of the 18CrNiMo 7-6 steel quenching in the oil. The end point of the trajectory is marked as zero point. Numbers in the picture indicate soaking time of carburizing: $1=2$ hours, $2=4$ hours, $3=6$ hours, $4=9$ hours,

$$
5=12 \text { hours }
$$

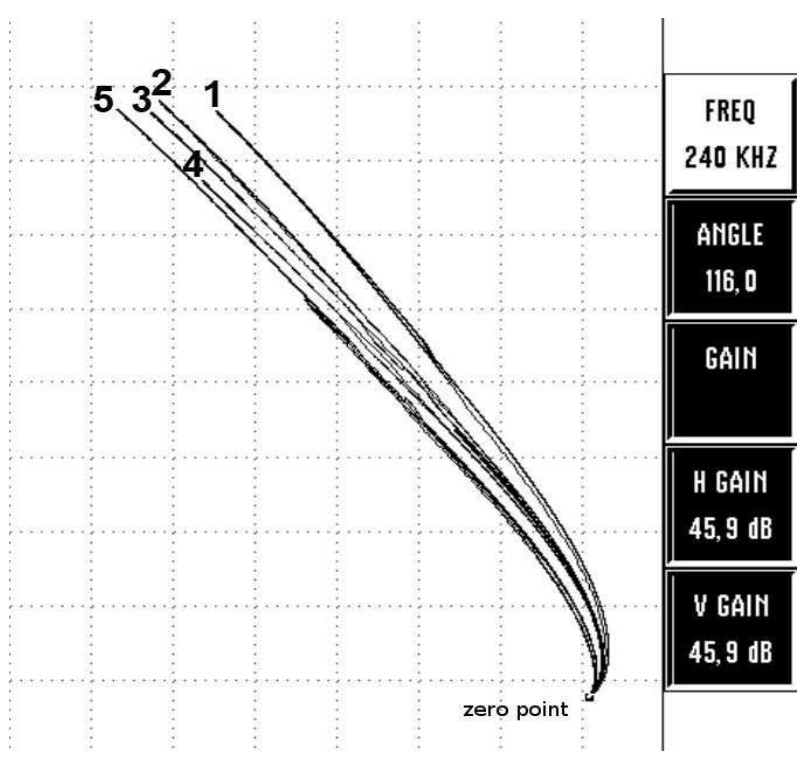

Fig. 2 Influence of carburizing depth on the trajectory of the working point in the impedance plane for variously samples of the 18CrNiMo 7-6 steel quenching in the water. The end point of the trajectory is marked as zero point. Number in the picture indicate soaking time of carburizing: $1=2$ hours, $2=4$ hours, $3=6$ hours, $4=$ 9 hours, $5=12$ hours

For verification and quantification of carburizing process was used universal eddy current flaw detector Nortec 500D. Absolute and differential measurement probes were used. Since the depth of the eddy current inflow is inversely proportional to the frequency of the excitation of the probe, it was necessary to choose measurement with the low frequencies. Quantification of individual samples, ie different parameters of the carburizing process, was performed by comparing the individual various movements of the working point within the phasor diagram. The depth of carburizing layers creates a unique trajectory of motion of the working point in this diagram, as this trajectory is strongly affected by the depth of carburizing. The trajectories of the movement of the working points for the individual samples is shown in Fig. 1,2. Assuming the existence of a sufficient number of test standards for which the depth of the carburizing layer is known, the carburizing depths of the individual real test specimens can be easily quantified in this way. Furthermore, the experiment found that the presence of the coated and decarburized layer did not affect the accuracy of measuring the depth and quality of the carburizing. The ability to determine the quality and depth of carburizing by eddy current measuring was subsequently verified on a real gear wheel made from the same material as the above-mentioned samples.

\section{Experimental - detecting the amount of reta- ined austenite}

Measuring of the amount of retained austenite is now undoubtedly a very problematic and unresolved problems in material engineering. Generally, the negative effect of the presence of retained austenite in steels is well known, whereby this undesirable structural component contributes, for example, to the instability of the dimensions of the components and the semi-products, the insufficient hardness of the steel after the hardening process, etc. There are many methods of quantification of retained austenite based mainly on microscopic observation of samples (EBSD, image analysis in LM), but these methods are not only time-consuming in terms of preparing usable samples, but above all provide often conflicting results. The only relevant method for accurate and repeatable evaluation of residual austenite is the so-called austenitemeter. However, the measurement with this instrument is still very expensive, especially when it is necessary to measure a large sample of samples. Because the austenite has markedly different physico-mechanical properties compared to the martensitic matrix, it is again possible to use the method of eddy currents for its identification and quantification.

In order to verify the possibility of using the method of measuring the eddy currents for the determination of the residual austenite quantity, an experiment was carried out using the powder carburizing of two types of steels: $16 \mathrm{MnCr} 5$ and $15 \mathrm{NiCr} 13$. These steels are commonly carburized and characterized by an increased residual austenite content in their microstructure after the heat treatment process. Experimental samples from both types of steels were subjected to powder carburizing at $910^{\circ} \mathrm{C}$ for 6 hours. After carburizing samples were quenched in oil from 3 different temperatures: $880^{\circ} \mathrm{C}, 920^{\circ} \mathrm{C}, 950^{\circ} \mathrm{C}$. A metallographic structure analysis using LM was determined for test specimens, confirming the increasing percentage of residual austenite with the increasing quenching temperature. Fig. 3 shows metallographic structure of steel $15 \mathrm{NiCr} 13$ quenching from $920^{\circ} \mathrm{C}$. From this figure is clear that the amount of retained austenite can not be exactly estimated.

For the experimental measurement, the same eddy 
current equipment was used as in the case of measuring the depth of carburizing in the previous chapter. Absolute probes were used for the measurements, with higher frequency of the excitation of the measuring coil. In contrast with measuring the depth of carburizing, it was more difficult in this case to optimize the measurement parameters so that the individual samples containing different proportions of retained austenite will be clearly distinguishable. Fig. 4,5 show the differences in the operating point trajectories of each type of steel for the different quench modes in the impedance measuring plane. These differences are due to the presence of varying amounts of retained austenite in the structure of experimental samples.

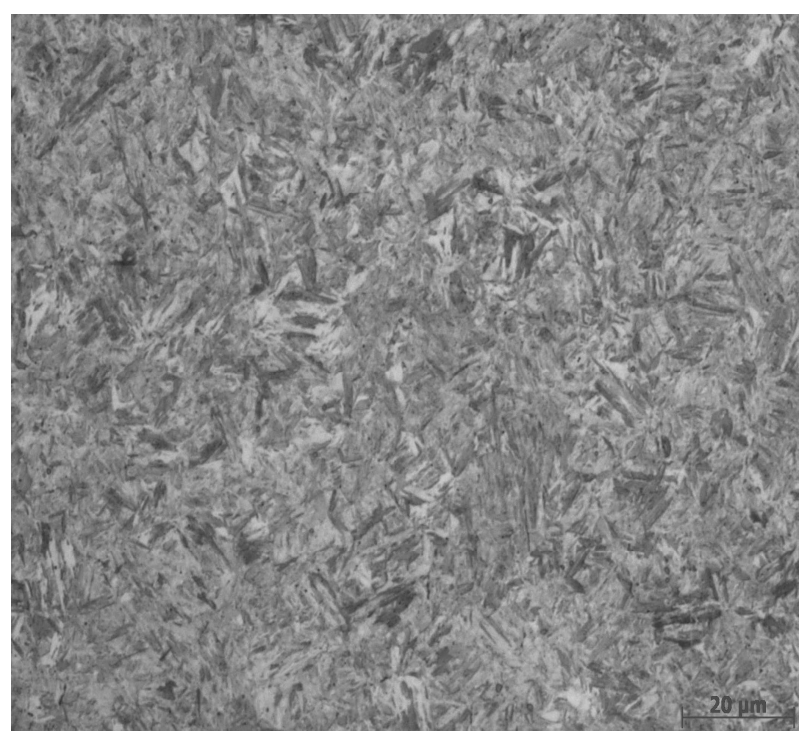

Fig. 3 Metallographic structure of steel $15 \mathrm{NiCr} 13$ quenching from $920^{\circ} \mathrm{C}$

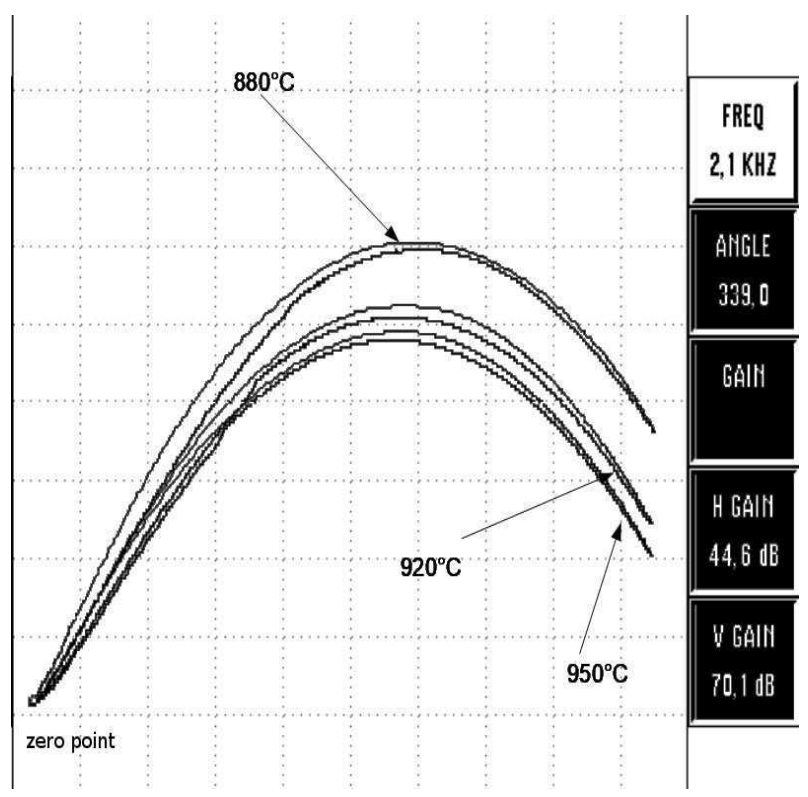

Fig. 4 Influence of amounts of retained austenite on the trajectory of the working point in the impedance plane for samples of the $15 \mathrm{NiCr} 13$ steel quenching in the oil. The end point of the trajectory is marked as zero point. The temperatures shown in the figure correspond to the quenching temperature of the samples

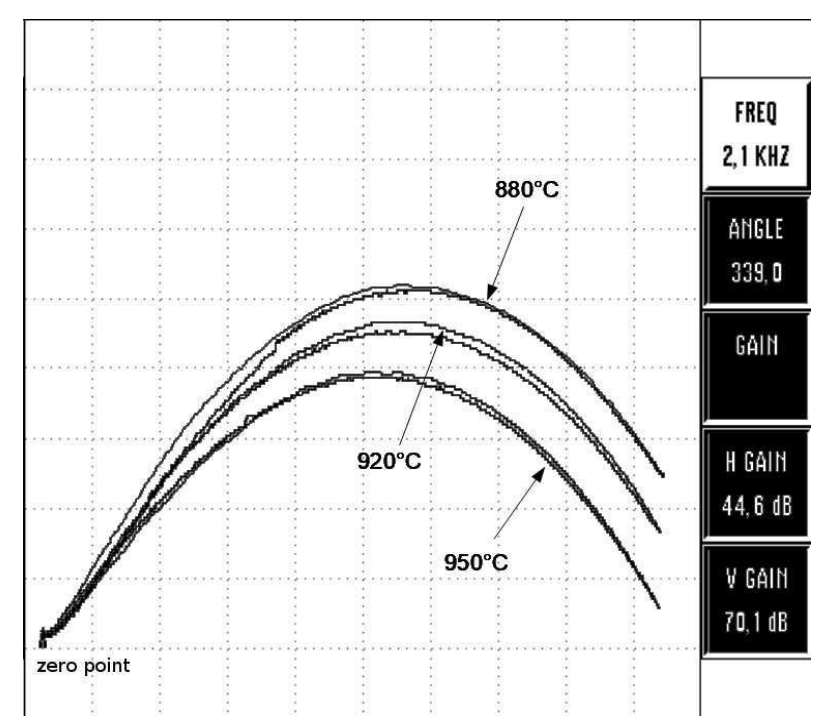

Fig. 5 Influence of amounts of retained austenite on the trajectory of the working point in the impedance plane for samples of the 16MnCr5 steel quenching in the oil. The end point of the trajectory is marked as zero point. The temperatures shown in the figure correspond to the quenching temperature of the samples

\section{Conclusion}

The above mentioned experiments confirmed the real possibility of using the eddy current method for verifying the important outputs of the thermal or chemical heat treatment processes, including checking the correctness of the carburizing process and achieving the desired depth of carburizing and determining the retained austenite. Experimental measurements were made using a ordinarily used eddy current defectoscope and probes commonly used to detect material defects. This fact also implies the very important fact that the use of this universal device is an economically very effective solution, since one device can cover another area of its use, and it is not necessary to invest in the purchase of a single-purpose machine. The only actual problem that can be seen in the use of eddy currents for such tasks is the need to produce a standard set - etalons of experimental samples, which can then accurately quantify the parameters of the product or semiproduct which are tested. This is, of course, problematic in determining the amount of retained austenite, because in this case the amount of retained austenite decreases with time.

It is also important to mention that the method of verifying the depth of carburizing by using the eddy current is successfully used in one czech engineering company.

\section{Acknowledgement}

The presented work was financially supported by the Ministry of Education, Youth and Sport Czech Republic - project LQ1603 Research for SUSEN. This work has been realized within the SUSEN Project (established in the framework of the European Regional Development Fund (ERDF) in project CZ.1.05/2.1.00/03.0108 and of the European Strategy Forum on Research Infrastructures (ESFRI) in the project CZ.02.1.01/0.0/0.0/15_008/0000293. 


\section{References}

[1] HÁJEK, J., KŘÍŽ, A., JIRKA, T. (2016). Distortion after Case Hardening of Steel, Manufacturing technology, Vol.16, No.4, pp. 697 - 702.

[2] BENEŠ, P., KOTRBA, M., KŘÍŽ,A. (2016). Alternative Uses of Eddy Current Inspection in Materials Engineering, Manufacturing technology, Vol.16, No.6, pp. 1240 - 1243.

[3] BELLANOVA, M., CARBONI, M., FELICETTI, R. A Feasibility analysis on the Application of Eddy Current Testing to the Detection of the Most Detrimental Defects in Historical metallic TieRods, NDT and E International, Volume 104, pp. $34-41,2019$.
[4] NOVÁKOVÁ, L., BOHÁČOVÁ, M., HOMOLA, P. Application of materials analysis and eddy current conductivity tests to aircraft accident investigation, Engineering Failure Analysis, Volume 56, pp. $422-428,2015$.

[5] BERGER, D., WILL, T., TOPPER, H.-CH., LANZA, G., KOSTER, D., HERRMANN, H.-G. Characterisation and Optimization of In-process Eddy Curremt Sensor Arrays Using Computed Tomography, Procedia CIRP 66, pp. 243 - 248, 2017.

[6] MACHADO, M.,A., ANTIN, K.-N., ROSADO, L.A., VILACA, P., SANTOS, T.G. Contactless High-Speed Eddy Current Inspection of Unidirectional Carbon Fiber Reinforced Polymer, Composites Part B: Engineering, Volume 168, pp. 226 $-235,2019$. 